BMJ Open Sport \& Exercise Medicine

\section{Echocardiographic measurements of left ventricular end-diastolic diameter and interventricular septal diameter in collegiate football athletes at preparticipation evaluation referenced to body surface area}

To cite: Edenfield KM, Reifsteck F, Carek S, et al. Echocardiographic measurements of left ventricular end-diastolic diameter and interventricular septal diameter in collegiate football athletes at preparticipation evaluation referenced to body surface area. BMJ Open Sport \& Exercise Medicine 2019;5:e000488. doi:10.1136/ bmjsem-2018-000488

Accepted 3 March 2019
Check for updates

C Author(s) (or their employer(s)) 2019. Re-use permitted under CC BY-NC. No commercial re-use. See rights and permissions. Published by BMJ.

For numbered affiliations see end of article.

Correspondence to Dr Katherine M Edenfield; kedenfield@ufl.edu

\section{ABSTRACT}

Background Are borderline echocardiogram structural measurements due to physiological adaptation or pathology in college football players? The normal reference data are very limited in this population. We report left ventricular end-diastolic diameter (LVEDD) and interventricular septal diameter (IVSD) echocardiogram findings in college football athletes.

Methods and results $A$ retrospective cohort review of preparticipation examination transthoracic echocardiogram measurements of LVEDD and IVSD from 375 American collegiate football athletes cleared for participation from the University of Florida in 2012-2017 and University of Georgia in 2010-2015 was performed.

LVEDD and IVSD were analysed by field position (lineman, $n=137$; non-lineman, $n=238$ ), race (black, $n=216$; white, $n=158$ ) and body surface area (BSA) for associations. Values were compared with non-athlete norms, and collegiate football athlete-specific reference norm tables were created. Twenty-one (5.6\%) athletes had LVEDD and 116 (31\%) had IVSD measurements above the reference normal non-athlete values. Univariate analyses indicated that the lineman position and increasing BSA were associated with larger values for LVEDD and IVSD. Black race was associated with larger IVSD values, and white race was associated with larger LVEDD values. Player position correlated strongly with BSA ( $r>0.7)$; we created normal reference tables for LVEDD and IVSD, stratified by BSA group classification (low, average and high BSA). Proposed clinical cut-offs for normal and abnormal values are reported for raw echocardiograph metrics and BSA-indexed scores.

Conclusions A significant number of collegiate football athletes had LVEDD and IVSD values above non-athlete norms. BSA-specific normal values help clinicians interpret results for football athletes.

\section{INTRODUCTION}

Professional sports leagues and collegiate institutions are increasingly using

\section{What are the new findings?}

- This study, involving one of the largest cohorts of American collegiate football players with echocardiographic data to date, reviewed left ventricula end-diastolic diameter (LVEDD) and interventricular septal diameter (IVSD) measurements, two parameters for which abnormal values can be associated with cardiomyopathies and subsequent sudden cardiac death.

- Current non-athlete norms for echocardiographic measurements of IVSD and LVEDD are likely not applicable to collegiate football athletes as a significant portion of these athletes may have 'borderline' or elevated values without underlying structural cardiovascular disease.

- Indexing IVSD and LVEDD to body surface area may provide a more specific measurement and limit the number of false-positive echocardiographic findings.

transthoracic echocardiography in their routine preparticipation evaluation (PPE) of athletes ${ }^{1}$ for structural conditions which predispose to sudden cardiac death (SCD). Despite this growing use, normal reference measurements for echocardiograms in collegiate athletes who play American football are not readily available. Normal values from non-athletic populations, ${ }^{2}$ non-football athletes $^{3-6}$ and professional football athletes ${ }^{7}$ are available, but many of these lack values stratified by race, player position or measures of body size. At present, the unknown prognostic significance of atypical or traditionally borderline abnormal structural findings seen on athlete echocardiograms limits their usefulness in screening and may lead to additional unnecessary testing. 
Participation in intense, repetitive physical activities is known to alter the structural characteristics of the heart with varying degrees of concentric or eccentric hypertrophy depending on the form of training. ${ }^{8}$ When benign, these adaptations are commonly referred to as 'athlete's heart'. ${ }^{9}$ The extent of change in cardiac dimensions varies between athletes and training methods, adding to the clinical dilemma of distinguishing athlete's heart from pathological heart disease. Much of the previous research looking at structural features of athlete's heart does not include American-style football (ASF), which in the USA has one of the highest rates of $\mathrm{SCD}^{1011}$ and where there are often issues of differentiating hypertrophic cardiomyopathy (HCM) from physiological hypertrophy (athlete's heart). The morphological features of HCM may not appear until physical maturation ${ }^{12} 13$ occurring at the college age, making this a critical time for screening. Studies that have looked at football have mostly been done in professional or retired professional football populations, ${ }^{7115}$ and athletes with HCM may have presented prior to these time points.

In addition to adaptations from exercise, cardiac dimensions may be related to body size. A larger person may have proportionally larger cardiac measurements regardless of training effects. ${ }^{716}$ This body size discrepancy between the general population and collegiate football athletes could contribute to difficulty distinguishing normal from abnormal echocardiogram findings, which have traditionally not been stratified by body size.

We sought to contribute to reference values by reporting echocardiographic findings of left ventricular end-diastolic diameter (LVEDD) and interventricular septal diameter (IVSD) in collegiate football athletes at the time of their PPE. We chose to examine these measures due to their association with cardiomyopathy and their ease of view with echocardiography. These values have also been investigated previously in professional football players ${ }^{7}$ and basketball players. ${ }^{6}$ We looked to build on this work and determine the applicability of current non-athlete echocardiogram norms to our sample of collegiate football athletes.

\section{METHODS}

Transthoracic echocardiographic data from American football athletes in the University of Florida Athletic Association Cardiac Databank collected between 2012 and 2017 were combined with similar, de-identified data from the University of Georgia collected between 2010 and 2015. The data analysed were from the time of PPE, which in addition to a full echocardiogram also included a personal and family history, physical exam, and ECG. All athletes received full clearance to play in the PPE period, and none were known to have been excluded during their subsequent career to the date of data extraction.

The majority of studies $(>60 \%)$ were performed in-mass by Athletic Heart ${ }^{17}$ during screening days held at each institution. Athletes who missed these screening days had echocardiograms performed on a GE Vivid E9 echocardiography machine with an M5 cardiac probe at each institution's designated cardiology office. All echocardiograms were read by cardiologists at the athlete's institution. Twelve different cardiologists contributed to interpreting these studies, with the breakdown of percentage read by each as follows: $49 \%, 35 \%, 9 \%, 2 \%$, $2 \%$ and seven cardiologists each reading $<1 \%$ of the total studies. Routine values were measured from a parasternal long-axis view as per the American Society of Echocardiography guidelines. ${ }^{2}$ Measurements were calculated initially by the echocardiographic technicians at the time of the study, with the interpreting cardiologist making corrections as needed before the final results were reported.

Height and weight were measured at the time of PPE. Demographic characteristics of race and position were noted for each subject. The race and position of the athletes were self-reported or determined through review of publicly available photographic roster information. ${ }^{18}{ }^{19}$ Subgroup analysis of race was confined to black and white athletes, as there was only one athlete in the data set of another race. Field position was classified as lineman (offensive/defensive guard, offensive/ defensive tackle, centre, defensive end or tight end) or non-lineman (running back, receiver, quarterback, linebacker, cornerback, safety, punter, kicker).

The primary outcome variables were LVEDD and IVSD measured in millimetres. Variables of interest included player position (dichotomised as linemen and non-linemen), race status (white and black), heart rate (HR; beats per minute), left ventricular ejection fraction (LVEF; \%), and body surface area $\left(\mathrm{BSA} ; \mathrm{m}^{2}\right)$ calculated as the square root of height in centimetres $\times$ weight in kilograms $/ 3600 .^{20}$ Since height and weight are used to calculate BSA and are thus strongly correlated, we elected to report only BSA. Given the homogeneity of ages in our sample (mean [SD] [range] 18.8 [1.0] [17-23] years), we did not assess for age effects.

\section{Statistical analyses}

All analyses were performed using the IBM SPSS V.24 statistical package. Independent samples t-tests were used to assess LVEDD and IVSD differences based on race and position. For continuous variables (BSA, HR and LVEF), Pearson bivariate correlations were used. Factors demonstrating a univariate association with a given outcome measure were considered for inclusion in a multiple linear regression. Prior to performing these regressions, we evaluated associations between independent variables using $\chi^{2}$ tests of categorical associations and bivariate correlations to avoid multicollinearity.

A primary goal of this study was to determine whether LVEDD and IVSD normal reference values for non-athletes applied to our collegiate football athletes. First, we evaluated whether differences existed between the current study's sample and normal values derived from non-athlete samples for LVEDD and IVSD. Cohen's $d$ was calculated as an indicator of the magnitude of the 
Table 1 General characteristics of collegiate football players

\begin{tabular}{|c|c|c|c|c|c|c|c|}
\hline \multirow[b]{3}{*}{ Characteristics } & \multirow{3}{*}{$\begin{array}{l}\begin{array}{l}\text { Overall } \\
\mathrm{N}=375\end{array} \\
\begin{array}{l}\text { Mean (SD) } \\
\text { (range) }\end{array}\end{array}$} & \multicolumn{2}{|l|}{ Race } & \multirow[b]{3}{*}{ P value* } & \multicolumn{2}{|l|}{ Position group } & \multirow[b]{3}{*}{ P value* } \\
\hline & & $\begin{array}{l}\text { Black } \\
\mathrm{n}=216\end{array}$ & $\begin{array}{l}\text { White } \\
\mathrm{n}=158\end{array}$ & & $\begin{array}{l}\text { Non-linemen } \\
\mathrm{n}=238\end{array}$ & $\begin{array}{l}\text { Linemen } \\
\mathrm{n}=137\end{array}$ & \\
\hline & & \multicolumn{2}{|l|}{$\begin{array}{l}\text { Mean (SD) } \\
\text { (range) }\end{array}$} & & \multicolumn{2}{|l|}{$\begin{array}{l}\text { Mean (SD) } \\
\text { (range) }\end{array}$} & \\
\hline Age, years & $\begin{array}{l}18.8(1.0) \\
(16-23)\end{array}$ & $\begin{array}{l}18.7(0.8) \\
(17-21)\end{array}$ & $\begin{array}{l}19.1(1.2) \\
(17-23)\end{array}$ & $<0.001$ & $\begin{array}{l}18.9(1.1) \\
(17-23)\end{array}$ & $\begin{array}{l}18.7(0.9) \\
(17-21)\end{array}$ & 0.026 \\
\hline Height, cm & $\begin{array}{l}186.6(6.8) \\
(167.6-203.2)\end{array}$ & $\begin{array}{l}186.5(6.5) \\
(167.6-203.2)\end{array}$ & $\begin{array}{l}186.8(7.1) \\
(170.1-200.7)\end{array}$ & 0.639 & $\begin{array}{l}183.8(5.9) \\
(167.6-196.9)\end{array}$ & $\begin{array}{l}191.7(5.0) \\
(179.7-203.2)\end{array}$ & $<0.001$ \\
\hline Weight, kg & $\begin{array}{l}102.3(20.9) \\
(61.2-162.2)\end{array}$ & $\begin{array}{l}102.9(21.0) \\
(66.9-162.2)\end{array}$ & $\begin{array}{l}101.5(20.7) \\
(61.2-155.4)\end{array}$ & 0.542 & $\begin{array}{l}90.6(10.8) \\
(61.2-125.9)\end{array}$ & $\begin{array}{l}122.7(18.3) \\
(77.1-162.2)\end{array}$ & $<0.001$ \\
\hline $\mathrm{BSA}, \mathrm{m}^{2}$ & $\begin{array}{l}2.29(0.26) \\
(1.72-2.94)\end{array}$ & $\begin{array}{l}2.30(0.26) \\
(1.84-2.93)\end{array}$ & $\begin{array}{l}2.29(0.26) \\
(1.72-2.94)\end{array}$ & 0.645 & $\begin{array}{l}2.1(0.15) \\
(1.72-2.56)\end{array}$ & $\begin{array}{l}2.55(0.21) \\
(1.97-2.94)\end{array}$ & $<0.001$ \\
\hline Heart rate, bpm & $\begin{array}{l}68.9(12.2) \\
(41-121)\end{array}$ & $\begin{array}{l}68.0(12.5) \\
(41-121)\end{array}$ & $\begin{array}{l}69.9(11.8) \\
(48-106)\end{array}$ & 0.130 & $\begin{array}{l}67.5(12.1) \\
(41-121)\end{array}$ & $\begin{array}{l}71.1(12.0) \\
(48-105)\end{array}$ & 0.006 \\
\hline LVEF & $\begin{array}{l}59.6(5.0) \\
(48-80)\end{array}$ & $\begin{array}{l}59.5(4.9) \\
(50-80)\end{array}$ & $\begin{array}{l}59.8(5.1) \\
(48-78)\end{array}$ & 0.510 & $\begin{array}{l}59.6(5.1) \\
(50-80)\end{array}$ & $\begin{array}{l}59.7(4.7) \\
(48-76)\end{array}$ & 0.884 \\
\hline
\end{tabular}

*Demographic characteristic differences assessed using independent samples t-test.

BSA, body surface area; LVEF, left ventricle ejection fraction; bpm, beats per minute.

sample differences by extracting the LVEDD and IVSD mean, SD, and associated sample size data from previously published non-athlete normal references ${ }^{2}$ and comparing with our sample's measurements.

We then further investigated demographic-specific influences on the current sample's LVEDD and IVSD values. If a given factor explained significant variance in LVEDD and IVSD, then that factor was used to create a more representative reference value tables. We established an a priori requirement of at least a medium effect size association (Cohen's $d>0.5$ or $r>0.3$ ) as our criteria for factor-specific reference tables. We report raw LVEDD and IVSD measurements as well as measurements indexed to BSA for clinical reference.

\section{Patient and Public Involvement Statement}

This research was done without patient involvement. Patients were not invited to comment on the study design and were not consulted to develop patient relevant outcomes or interpret the results. Patients were not invited to contribute to the writing or editing of this document for readability or accuracy.

\section{RESULTS}

We included 375 male collegiate football athletes $(58 \%$ black, 63\% non-linemen). Table 1 shows descriptive statistics of demographic and primary independent variables for the overall sample, stratified by race and position. As expected, linemen had significantly greater height, weight and BSA than non-linemen. LVEDD and IVSD showed a normal distribution (figure 1).

\section{Determination of appropriateness of non-athletic norms}

Our overall collegiate football athlete sample showed larger LVEDD (Cohen's $d=0.512$, medium effect) and
IVSD ( $d=1.69$, large effect) values than non-athlete reference values. A percentage of athletes in each category (LVEDD 5.6\%; IVSD 31\%) had abnormal values (LVEDD $>58 \mathrm{~mm}$; IVSD $>10 \mathrm{~mm}$ ) as defined in a non-athlete population, ${ }^{2}$ none of which were determined to have cardiac pathology. This suggests that non-athlete reference data may not be appropriate for this population when interpreting upper values of LVEDD and IVSD.

\section{Independent effects of race, position and BSA}

Significant differences existed within race and position groups (table 2). Univariate analyses of race indicated that white players had significantly higher LVEDD (Cohen's $d=0.27$, small effect size) and lower IVSD ( $d=0.34$, small effect) than black players. For position, linemen exhibited significantly higher LVEDD ( $d=0.55$, medium effect) and IVSD (Cohen's $d=0.62$, medium-large effect) than non-linemen. Because BSA correlates very strongly with height $(\mathrm{r}=0.736, \mathrm{p}<0.001)$ and weight $(\mathrm{r}=0.991, \mathrm{p}<0.001)$, only BSA effects were further evaluated. Similar results showing differences within race and position groups were found when using BSA-indexed scores instead of raw scores (table 3).

BSA correlated positively with LVEDD ( $\mathrm{r}=0.377$, $\mathrm{p}<0.001$, medium effect) and IVSD ( $\mathrm{r}=0.421, \mathrm{p}<0.001$, medium-large effect). No associations between HR or LVEF and LVEDD and IVSD were observed.

Taken together, race, position and BSA were all significantly associated with LVEDD and IVSD. $\chi^{2}$ analyses indicated no association between race and position $\left(\chi^{2}[1,375]=0.196, p=0.658\right)$. However, position and BSA correlated very strongly $(r=0.750, p<0.001$, large effect), suggesting likely multicollinearity effects. BSA was used 
A

Left Ventricle Dimension

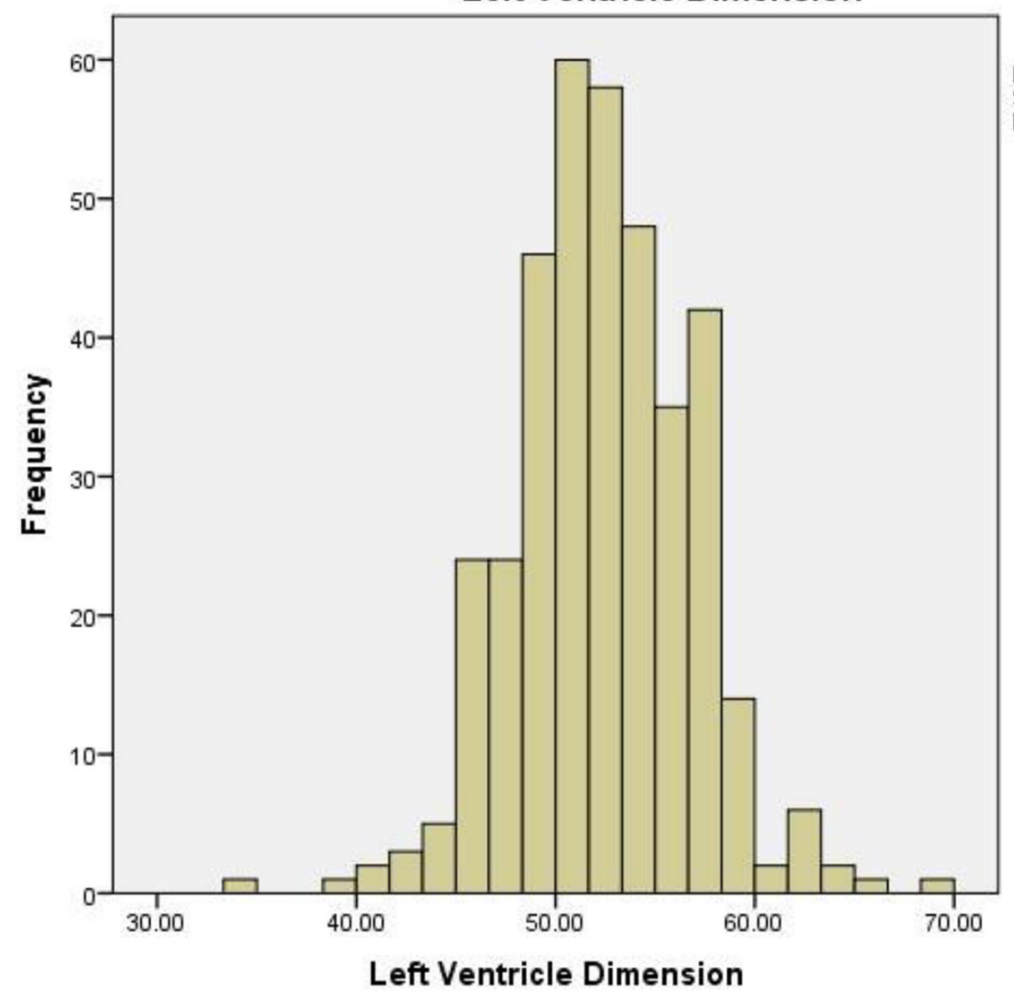

Mean $=52.40$

Std. Dev. $=4.506$

$\mathrm{N}=375$

B

Interventricular Septum

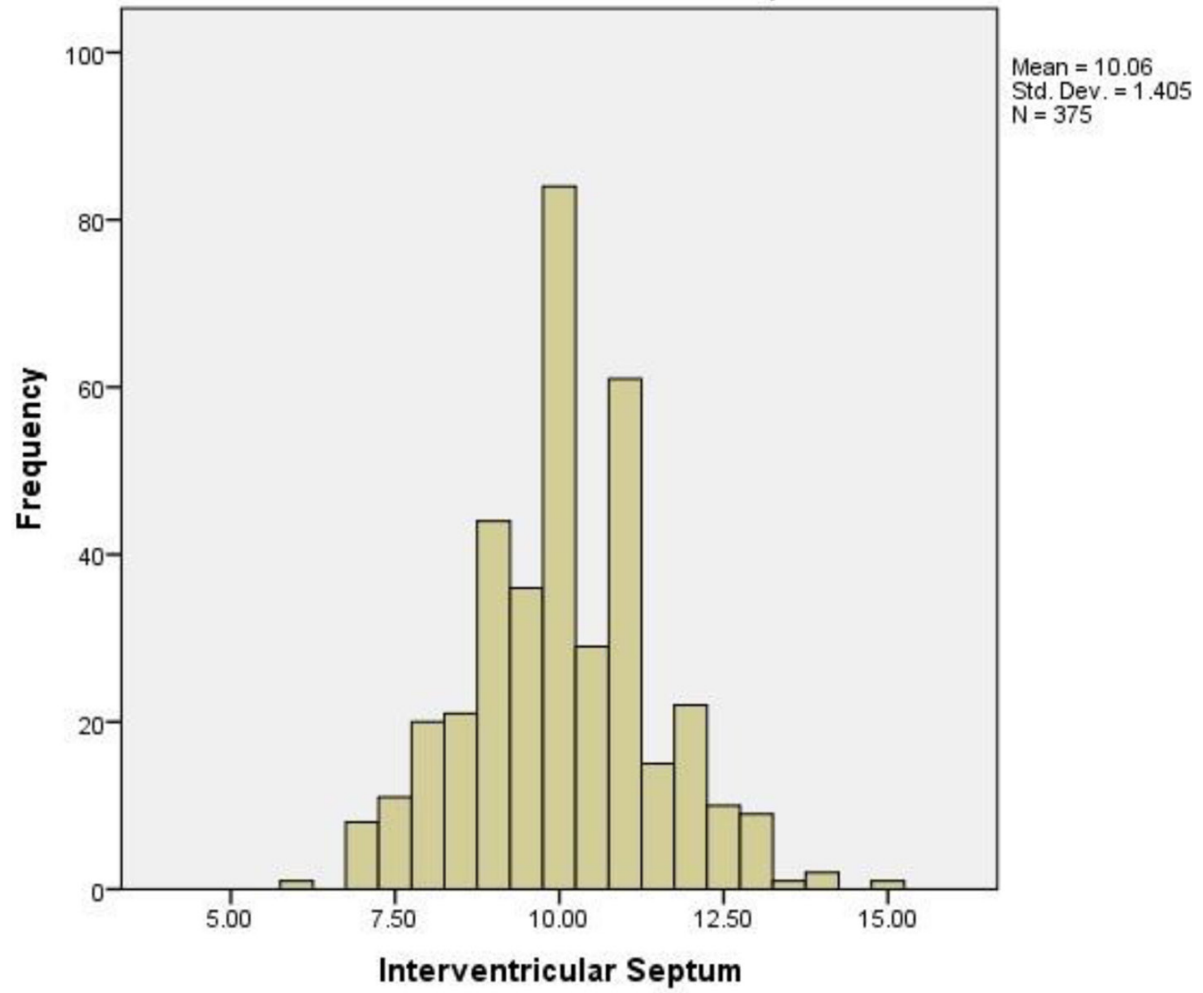

Figure 1 Histograms of (A) left ventricular end-diastolic diameter and (B) interventricular septal diameter in collegiate football athletes. 
Table 2 Echocardiogram characteristics of collegiate football players

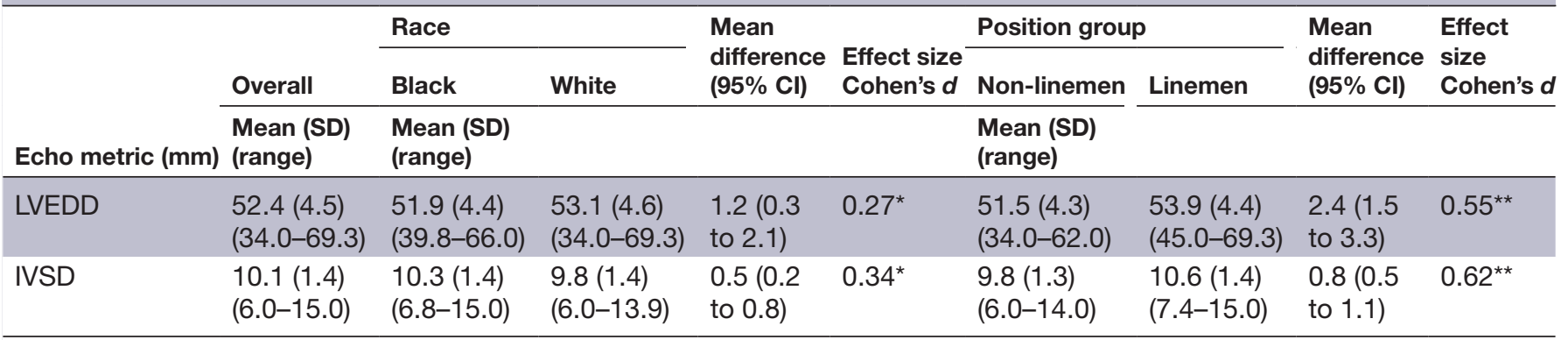

Sample size (n) for LVEDD and IVSD: overall (375), black (216), white (158), non-linemen (238) and linemen (137).

${ }^{*} \mathrm{P}<0.01,{ }^{* *} \mathrm{p}<0.001$.

IVSD, interventricular septum diameter; LVEDD, left ventricular end-diastole diameter.

rather than position in subsequent regression analyses based on previous research highlighting the importance of $\mathrm{BSA}^{6}$ and investigator consensus that one would expect two people with similar BSA to have similar LVEDD/ IVSD, regardless of what position they play, with far more confidence than one would expect two people playing the same position to have similar LVEDD/IVSD even if their BSA was drastically different.

\section{Multiple regression results}

For analysis of the association between BSA and race with LVEDD, the overall model was significant $\left(F[2,371]=35.948, \mathrm{r}^{2}=0.162, \mathrm{p}<0.001\right)$. Both race $(\beta=0.144, \quad p=0.003$, small effect $)$ and BSA $(\beta=0.380$, $\mathrm{p}<0.001$, medium effect) were independently associated with LVEDD even while controlling for each other; BSA was the stronger of the two. Every $0.259 \mathrm{~m}^{2}$ increase in BSA was associated with a $1.71 \mathrm{~mm}$ increase in LVEDD.

For IVSD, the overall model was significant $\left(F[2,371]=46.938, \quad \mathrm{r}^{2}=0.202, \quad \mathrm{p}<0.001\right) . \quad$ Both race ( $\beta=-0.157, p=0.001$, small effect) and BSA $(\beta=0.417$, $\mathrm{p}<0.001$, medium-large effect) remained significantly associated with IVSD while controlling for each other; BSA was the stronger of the two. Every $0.259 \mathrm{~m}^{2}$ increase in BSA was associated with a $0.59 \mathrm{~mm}$ increase in IVSD.

Overall, BSA had a stronger association than race with LVEDD and IVSD. We concluded that BSA should be considered when experts create normal reference values for these echocardiogram measures. We transformed BSA into a categorical factor based on 1 SD cut-points in the BSA distribution, creating below-average $(\mathrm{Z}<-1)$, average $(-1<\mathrm{Z}<1)$ and above-average $(\mathrm{Z}>1)$ reference groups.

\section{Normal reference values for collegiate football athletes stratified by BSA group}

Analyses of variance confirmed that the BSA groupings preserved the linear association between BSA and LVEDD $(F[2,372]=20.026, \mathrm{p}<0.001)$ and $\operatorname{IVSD}(F[2,372]=25.202$, $\mathrm{p}<0.001)$. We made additional comparisons with non-athlete reference ranges using the BSA subgroups in our football athlete sample. For LVEDD, significantly higher values for football athletes were noted for average $(d=0.470$, medium effect $)$ and above-average $(d=1.26$, large effect), but not below-average $(d=0.076$, negligible effect). For IVSD, large effects were noted for the below-average $(d=1.02)$, average $(d=1.80)$ and above-average $(d=2.31)$ BSA groups.

Tables 4 and 5 show ranges for 'normal' and possible 'abnormal' cut-offs for each reference group, using both raw LVEDD and IVSD values, as well as index scores for BSA. Values were determined to be 'normal' if they fell before the 95th percentile in the distribution, or all values with a Z-score less than 1.6. 'Mildly Abnormal', 'Moderately Abnormal' and 'Severely Abnormal' were defined by values falling in the 95 th-98th percentile $(1.6<\mathrm{Z}<2.0)$,

Table 3 Echocardiogram characteristics of collegiate football players indexed to BSA

\begin{tabular}{|c|c|c|c|c|c|c|c|c|c|}
\hline \multirow{3}{*}{$\begin{array}{l}\text { Echo } \\
\text { metric/BSA } \\
\left(\mathrm{mm} / \mathrm{m}^{2}\right)\end{array}$} & \multirow[b]{2}{*}{ Overall } & \multicolumn{2}{|l|}{ Race } & \multirow{2}{*}{$\begin{array}{l}\text { Mean } \\
\text { difference } \\
(95 \% \mathrm{Cl})\end{array}$} & \multirow{2}{*}{$\begin{array}{l}\text { Effect } \\
\text { size } \\
\text { Cohen's } \\
d\end{array}$} & \multicolumn{2}{|l|}{ Position group } & \multirow{2}{*}{$\begin{array}{l}\text { Mean } \\
\text { difference } \\
(95 \% \mathrm{Cl})\end{array}$} & \multirow{2}{*}{$\begin{array}{l}\text { Effect } \\
\text { size } \\
\text { Cohen's } \\
d\end{array}$} \\
\hline & & Black & White & & & Non-linemen & Linemen & & \\
\hline & $\begin{array}{l}\text { Mean (SD) } \\
\text { (range) }\end{array}$ & $\begin{array}{l}\text { Mean (SD) } \\
\text { (range) }\end{array}$ & & & & $\begin{array}{l}\text { Mean (SD) } \\
\text { (range) }\end{array}$ & & & \\
\hline LVEDD & $\begin{array}{l}23.0(2.6) \\
(14.5-32.0)\end{array}$ & $\begin{array}{l}22.8(2.6) \\
(17.1-29.7)\end{array}$ & $\begin{array}{l}23.4(2.5) \\
(14.5-32.0)\end{array}$ & $\begin{array}{l}0.66(0.13 \\
\text { to } 1.2)\end{array}$ & $0.24^{*}$ & $\begin{array}{l}24.1(2.3) \\
(14.5-32.0)\end{array}$ & $\begin{array}{l}21.3(2.0) \\
(17.1-27.7)\end{array}$ & $\begin{array}{l}2.8(2.4 \text { to } \\
3.3)\end{array}$ & $1.30^{\star \star}$ \\
\hline IVSD & $\begin{array}{l}4.41(0.61) \\
(2.97-6.45)\end{array}$ & $\begin{array}{l}4.49(0.63) \\
(2.97-6.45)\end{array}$ & $\begin{array}{l}4.30(0.56) \\
(3.04-6.20)\end{array}$ & $\begin{array}{l}0.20(0.07 \\
\text { to } 0.32)\end{array}$ & $0.32^{*}$ & $\begin{array}{l}4.55(0.61) \\
(3.03-6.45)\end{array}$ & $\begin{array}{l}4.17(0.53) \\
(2.97-5.45)\end{array}$ & $\begin{array}{l}0.38(0.26 \\
\text { to } 0.51)\end{array}$ & $0.66^{\star \star}$ \\
\hline
\end{tabular}

Sample size (n) for LVEDD and IVS: overall (375), black (216), white (158), non-linemen (238) and linemen (137).

${ }^{*} \mathrm{P}<0.05,{ }^{* *} \mathrm{p}<0.001$

BSA, body surface area; IVSD, interventricular septum diameter; LVEDD, left ventricular end-diastole diameter. 
Table 4 LVEDD and IVSD reference values by BSA group

\begin{tabular}{|c|c|c|c|c|c|}
\hline \multirow{3}{*}{$\begin{array}{l}\text { Echo measure } \\
(\mathrm{mm})\end{array}$} & \multirow{3}{*}{$\begin{array}{l}\begin{array}{l}\text { Overall } \\
\text { sample }\end{array} \\
1.72-2.94 \mathrm{~m}^{2}\end{array}$} & \multicolumn{3}{|c|}{ BSA reference group } & \multirow{3}{*}{$\begin{array}{l}\text { General population } \\
\text { male } \\
\text { norms }^{2}\end{array}$} \\
\hline & & Below average & Average & Above average & \\
\hline & & $1.72-2.05 \mathrm{~m}^{2}$ & $2.06-2.57 \mathrm{~m}^{2}$ & $2.58-2.94 \mathrm{~m}^{2}$ & \\
\hline \multicolumn{6}{|l|}{ LVEDD } \\
\hline Normal & $<59.6$ & $<57.40$ & $<59.1$ & $<61.9$ & $42.0-58.0$ \\
\hline Mildly abnormal & $59.6-61.4$ & $57.4-59.1$ & $59.1-60.9$ & $61.9-63.5$ & $59.0-63.0$ \\
\hline Moderately abnormal & $61.5-63.7$ & $59.2-61.3$ & $61.0-63.0$ & $63.6-65.5$ & $64.0-68.0$ \\
\hline Severely abnormal & $>63.7$ & $>61.3$ & $>63.0$ & $>65.5$ & $>68.0$ \\
\hline \multicolumn{6}{|l|}{ IVSD } \\
\hline Normal & $<12.3$ & $<11.3$ & $<12.1$ & $<13.2$ & $6.0-11.0$ \\
\hline Mildly abnormal & $12.3-12.9$ & $11.3-11.8$ & $12.1-12.7$ & $13.2-13.8$ & $11.0-13.0$ \\
\hline Moderately abnormal & $13.0-13.6$ & $11.9-12.5$ & $12.8-13.3$ & $13.9-14.6$ & $14.0-16.0$ \\
\hline Severely abnormal & $>13.6$ & $>12.5$ & $>13.3$ & $>14.6$ & $>16.0$ \\
\hline
\end{tabular}

Our definitions for BSA reference groups:

Normal: $<95$ th percentile or $Z<1.6$.

Mildly abnormal: 95th-98th percentile or $1.6<Z<2.0$.

Moderately abnormal: 98 th-99th percentile or $2.0<Z<2.5$.

Severely abnormal: $>99$ th percentile or $Z>2.5$.

BSA, body surface area; IVSD, interventricular septum diameter; LVEDD, left ventricular end-diastole diameter.

98th-99th percentile $(2.0<\mathrm{Z}<2.5)$ and $>99$ th percentile $(\mathrm{Z}>2.5)$, respectively.

Of note, despite using the BSA index score in the current sample, we still observed the same linear association between BSA group and both echocardiogram measurements $(p<0.001$ for all main effects; below average $<$ average $<$ above average); this suggests that BSA group-specific reference values remain warranted even when using index scores that attempt to account for BSA differences. We once again compared our football athlete sample with non-athlete reference data, this time using BSA-indexed scores (available for LVEDD in non-athletes). For LVEDD/BSA, non-athlete values were much higher than our overall football athlete sample ( $d=1.28$, large effect), driven primarily by differences between non-athlete values and the average $(d=1.46$, large effect) and above average ( $d=3.20$, large effect) BSA groups.

\section{DISCUSSION}

It is challenging for clinicians to identify structural changes that predispose to SCD on echocardiogram

Table 5 LVEDD and IVSD indexed by BSA reference values by BSA group

\begin{tabular}{|c|c|c|c|c|c|}
\hline \multirow{3}{*}{$\begin{array}{l}\text { Echo index measure } \\
\left(\mathrm{mm} / \mathrm{m}^{2}\right)\end{array}$} & \multirow{3}{*}{$\begin{array}{l}\begin{array}{l}\text { Overall } \\
\text { sample }\end{array} \\
1.72-2.94 \mathrm{~m}^{2} \\
\end{array}$} & \multicolumn{3}{|c|}{ BSA reference group } & \multirow{3}{*}{$\begin{array}{l}\text { General population } \\
\text { male } \\
\text { norms }^{2}\end{array}$} \\
\hline & & Below average & Average & Above average & \\
\hline & & $1.72-2.05 \mathrm{~m}^{2}$ & $2.06-2.57 \mathrm{~m}^{2}$ & $2.58-2.94 \mathrm{~m}^{2}$ & \\
\hline \multicolumn{6}{|l|}{ LVEDD/BSA } \\
\hline Normal & $<27.2$ & $<29.3$ & $<26.3$ & $<22.8$ & $22.0-30.0$ \\
\hline Mildly abnormal & $27.2-28.2$ & $29.3-30.2$ & $26.3-27.2$ & $22.8-23.4$ & $31.0-33.0$ \\
\hline Moderately abnormal & $28.3-29.5$ & $30.3-31.4$ & $27.3-28.2$ & $23.5-24.2$ & $34.0-36.0$ \\
\hline Severely abnormal & $>29.5$ & $>31.4$ & $>28.2$ & $>24.2$ & $>36.0$ \\
\hline \multicolumn{6}{|l|}{ IVSD/BSA } \\
\hline Normal & $<5.4$ & $<5.8$ & $<5.3$ & $<4.8$ & NA \\
\hline Mildly abnormal & $5.4-5.6$ & $5.8-6.1$ & $5.3-5.6$ & $4.8-5.0$ & NA \\
\hline Moderately abnormal & $5.7-5.9$ & $6.2-6.4$ & $5.7-5.8$ & $5.1-5.2$ & NA \\
\hline Severely abnormal & $>5.9$ & $>6.4$ & $>5.8$ & $>5.2$ & NA \\
\hline
\end{tabular}

Normal: $<95$ th percentile or $Z<1.6$.

Mildly abnormal: 95 th-98th percentile or $1.6<Z<2.0$.

Moderately abnormal: 98th-99th percentile or $2.0<Z<2.5$.

Severely abnormal: >99th percentile or Z>2.5.

BSA, body surface area; IVSD, interventricular septum diameter; LVEDD, left ventricular end-diastole diameter; NA, not available. 
because exercise-related changes of cardiac structure may approach and even overlap current limits for non-athlete normal values. Factors that influence the degree of remodelling include training type, intensity and volume, as well as an athlete's physiological growth. ${ }^{21-23}$ These variables should be considered with interpretation of echocardiogram results. ASF athletes' cardiac adaptations have not been well defined, and this study attempted to do such with echocardiogram measurements of LVEDD and IVSD using a large cohort of collegiate ASF athletes.

An expected component of athlete's heart involves increases in left ventricular (LV) chamber size. ${ }^{92425}$ We found LVEDD athlete values were higher than non-athletes for raw LVEDD measurements, and that white race, lineman position and BSA were all significantly associated with larger LVEDD values, with BSA having the strongest association with LVEDD. While our LVEDD values were smaller than those reported by Haddad and colleagues ${ }^{26}$ in collegiate football players, our values indexed to BSA were very similar. We suggest using BSA reference groups to determine normal values as shown in tables 4 and 5 .

\section{What to do in the 'grey zone' of IVSD between 13 and $15 \mathrm{~mm}$ ?}

A long-standing area of uncertainty found in a small percentage of athletes is the 'grey zone' of IVSD between 13 and $15 \mathrm{~mm} .{ }^{1327}{ }^{28}$ We recommend clinicians focus on IVSD, as opposed to posterior wall thickness, average left ventricle wall thickness or maximal wall thickness as asymmetric septal hypertrophy is the most common phenotype in $\mathrm{HCM},{ }^{29}$ with the septum involved in up to $90 \%$ of cases. ${ }^{30}$

The original study that defined the grey zone was in an Italian cohort which did not include American football or black athletes, ${ }^{28}$ and all of the athletes with $\mathrm{LV}$ wall thickness $\geq 13 \mathrm{~mm}(<2 \%)$ were male rowers, canoeists or cyclists. Black athletes have a greater LV wall thickness than do white athletes, and this could lead to false-positive diagnosis of $\mathrm{HCM}^{31}$ in black athletes. In one of the largest $(n=129)$ and only studies of collegiate football players available, black athletes had greater IVSD measurements than did white $(8.3 \pm 0.9 \mathrm{~mm}$ vs $7.7 \pm 0.8 \mathrm{~mm})$ athletes ${ }^{26}$ which was similar to our findings (black: $10.3 \pm 1.4 \mathrm{~mm}$; white: $9.8 \pm 1.4 \mathrm{~mm}$ ) but our values were larger. BSA-indexed values were not available for comparison.

Lin and colleagues ${ }^{23}$ also reported smaller values for IVSD in lineman $(9.6 \pm 0.9 \mathrm{~mm})$ and non-lineman $(9.3 \pm 1.3 \mathrm{~mm})$ compared with our cohort (lineman: $10.6 \pm 1.4 \mathrm{~mm}$; non-lineman: $9.8 \pm 1.3 \mathrm{~mm})$. In our cohort, 10 athletes $(2.7 \%)$ had an IVSD of $13 \mathrm{~mm}$ or greater (7 black, 3 white; 7 lineman, 3 non-lineman), and 2 (0.5\%) had an IVSD of $14 \mathrm{~mm}$ or greater (2 black [1 lineman, 1 non-lineman]). Our findings suggest that abnormal IVSD as defined in a non-athlete population (IVSD $\geq 11 \mathrm{~mm})^{2}$ would not apply to this population of collegiate football players, and further suggest using BSA reference groups shown in tables 4 and 5 to define abnormal as greater than the $95 \%$ percentile.

\section{CONCLUSIONS}

We provide reference data for two important echocardiographic values in collegiate football players who underwent PPE. Non-athlete norms do not apply to LVEDD and IVSD values in this population. BSA has the strongest association with LVEDD and IVSD values. We suggest that LVEDD and IVSD values of collegiate football players that approach the upper limits of non-athlete norms should be interpreted in the context of BSA as shown in tables 4 and 5 . Our study will help clinicians distinguish normal echocardiographic findings and findings that reflect an increased risk of SCD in American football athletes who are starting their collegiate careers.

\section{Study limitations}

Although the sample is large, it did not include athletes from races other than blacks and whites, so may not apply to football athletes of other races. Both institutions compete in the National Collegiate Athletic Association (NCAA) Division I Football Bowl Subdivision, and our results may also not apply to other competition levels. We suspect that the majority of echocardiograms reflect adaptive changes seen from playing football through the high school level as the athlete's collegiate football careers were just beginning at the time of evaluation. Therefore, our results may not apply to different time points in football participation including youth, collegiate or professional. The echocardiogram measurements analysed were taken from those interpreted clinically and were not over-read by a single cardiologist for research purposes. Multiple cardiologists contributed to the interpretation of studies, but three cardiologists read $93 \%$ of the echocardiograms. These factors may lead to some inherent variability in the measurements. Our study evaluated two echocardiographic measurements known for changes in cardiomyopathies associated with SCD. However, various other metrics of cardiac function, such as right ventricular structure and function, and global longitudinal strain, were not accounted for. Other limitations include the lack of a comparison group of non-athletes with biometrics similar to this NCAA cohort, the study's cross-sectional design (no follow-up of those athletes whose cardiac variables were at the outer edges of distribution) and statistically derived abnormal cut-off values. Future studies with a more heterogeneous population comparing the effects of body size, ethnicity and age will help determine limits of normal physiological remodelling and create opportunities to refine the models we outline here. ${ }^{32}$ A future study would benefit from determining appropriate abnormal values based on the risk for developing cardiac complications in an athlete sample followed longitudinally.

\section{Author affiliations}

${ }^{1}$ Community Health and Family Medicine, University of Florida, Gainesville, Florida, USA

${ }^{2}$ University Athletic Association, University of Florida, Gainesville, Florida, USA

${ }^{3}$ Student Health Care Center, University of Florida, Gainesville, Florida, USA

${ }^{4}$ University Health Center, University of Georgia, Athens, Georgia, USA 
${ }^{5}$ Athletic Association, University of Georgia, Athens, Georgia, USA

${ }^{6}$ Family Medicine and Orthopaedics and Sports Medicine, University of Washington, Seattle, Washington, USA

${ }^{7}$ Clinical and Health Psychology, University of Florida, Gainesville, Florida, USA

${ }^{8}$ The Cardiac and Vascular Institute, Gainesville, Florida, USA

Acknowledgements The authors wish to thank Monica Towns for her help with obtaining informed consent, data collection and entry.

Contributors KE, FR, KH and JC contributed to the conception and the design of the study. KE, FR, SC, BMA, JS and JC contributed to the analysis and interpretation of the data. KE, FR, SC, KH, MD and JC drafted and revised the manuscript for important intellectual content. All authors approved the final submitted version of the manuscript.

Funding This work was supported in part by the American Medical Society for Sports Medicine (AMSSM) Foundation Research Grant 2016 awarded to KE, and the University of Florida REDCap uses the NIH National Center for Advancing Translational Sciences (NCATS) grant UL1 TR000064. Publication of this article was funded by the University of Florida Open Access Publishing Fund and the University of Florida Department of Community Health and Family Medicine.

Competing interests JS is a part-time consultant in the capacity of quality assurance technologist for Athletic Heart. For the remaining authors, no conflicts of interest were declared.

\section{Patient consent for publication Not required.}

Ethics approval The University of Florida Institutional Review Board and the University of Georgia Institutional Review Board.

Provenance and peer review Not commissioned; externally peer reviewed.

Data availability statement Any qualified investigator may contact the corresponding author (KE) or senior author (JC) with a specific request that includes details of (1) the resources requested, (2) how the data and resources will be used in the proposed research, and (3) the qualifications of the investigator requesting the resources. Investigators may be asked to provide further details if necessary. All requests will be reviewed for availability of the requested resources, potential for duplication of ongoing studies and scientific merit. Due to the multicentre nature of the study and FERPA and HIPPA concerns with this particular cohort, sharing data may be more complicated. The requesting investigator may be asked to partner with a University of Florida investigator and a University of Georgia investigator to better understand the available data, and will sometimes be encouraged to include a Florida and Georgia representative as an academic consultant or collaborator. Requesting investigators will also be required to sign a Data Use Agreement ensuring data will not be shared with third parties.

Open access This is an open access article distributed in accordance with the Creative Commons Attribution Non Commercial (CC BY-NC 4.0) license, which permits others to distribute, remix, adapt, build upon this work non-commercially, and license their derivative works on different terms, provided the original work is properly cited, appropriate credit is given, any changes made indicated, and the use is non-commercial. See: http://creativecommons.org/licenses/by-nc/4.0/.

\section{REFERENCES}

1. Terlep S. Worried about heart defects, some NCAA schools take action. Wall Street Journal 2015

2. Lang RM, Badano LP, Mor-Avi V, et al. Recommendations for cardiac chamber quantification by echocardiography in adults: an update from the American Society of echocardiography and the European association of cardiovascular imaging. J Am Soc Echocardiogr 2015;28:1-39

3. Maron BJ, Pelliccia A. The heart of trained athletes: cardiac remodeling and the risks of sports, including sudden death. Circulation 2006;114:1633-44.

4. Prior DL, La Gerche A. The athlete's heart. Heart 2012;98:947-55.

5. La Gerche A, Baggish AL, Knuuti J, et al. Cardiac imaging and stress testing asymptomatic athletes to identify those at risk of sudden cardiac death. JACC Cardiovasc Imaging 2013;6:993-1007.
6. Engel DJ, Schwartz A, Homma S. Athletic cardiac remodeling in US professional Basketball players. JAMA Cardiol 2016;1:80-7.

7. Abernethy WB, Choo JK, Hutter AM. Echocardiographic characteristics of professional football players. J Am Coll Cardiol 2003;41:280-4.

8. Mitchell JH, Haskell W, Snell P, et al. Task Force 8: classification of sports. J Am Coll Cardiol 2005;45:1364-7.

9. Pluim BM, Zwinderman AH, van der Laarse $A$, et al. The athlete's heart. A meta-analysis of cardiac structure and function. Circulation 2000;101:336-44.

10. Harmon KG, Asif IM, Klossner D, et al. Incidence of sudden cardiac death in national collegiate athletic association athletes. Circulation 2011;123:1594-600.

11. Harmon KG, Asif IM, Maleszewski JJ, et al. Incidence, cause, and comparative frequency of sudden cardiac death in national collegiate athletic association athletes: a decade in review. Circulation 2015:132:10-19.

12. Maron BJ, Spirito P, Wesley $\mathrm{Y}$, et al. Development and progression of left ventricular hypertrophy in children with hypertrophic cardiomyopathy. N Engl J Med 1986;315:610-4.

13. Maron BJ, Pelliccia A, Spirito P. Cardiac disease in young trained athletes. Insights into methods for distinguishing athlete's heart from structural heart disease, with particular emphasis on hypertrophic cardiomyopathy. Circulation 1995;91:1596-601.

14. Gentry JL, Carruthers D, Joshi PH, et al. Ascending aortic dimensions in former National Football League athletes. Circ Cardiovasc Imaging 2017;10.

15. Croft LB, Belanger A, Miller MA, et al. Comparison of National Football League linemen versus nonlinemen of left ventricular mass and left atrial size. Am J Cardiol 2008;102:343-7.

16. Crouse SF, White S, Erwin JP, et al. Echocardiographic and blood pressure characteristics of first-year collegiate American-Style football players. Am J Cardiol 2016;117:131-4.

17. Athletic heart. Available: www.athletic-heart.com

18. Association UoFA. Football roster. Available: floridagators.com

19. Association UoGA. Football roster. Available: http://georgiadogs. $\mathrm{com} /$

20. Mosteller RD. Simplified calculation of body-surface area. N Engl J Med 1987;317.

21. Kim JH, Hollowed C, Patel K, et al. Temporal changes in cardiovascular remodeling associated with football participation. Med Sci Sports Exerc 2018.

22. Weiner RB, DeLuca JR, Wang F, et al. Exercise-induced left ventricular remodeling among competitive athletes. Circ Cardiovasc Imaging 2015;8.

23. Lin J, Wang F, Weiner RB, et al. Blood pressure and left ventricular remodeling among American style football players 2016;9:1367-76.

24. La Gerche A, Taylor AJ, Prior DL. Athlete's heart: the potential for multimodality imaging to address the critical remaining questions. JACC Cardiovasc Imaging 2009;2:350-63.

25. Khan AA, Safi L, Wood M. Cardiac imaging in athletes. Methodist Debakey Cardiovasc J 2016;12:86-92.

26. Haddad F, Peter S, Hulme O, et al. Race differences in ventricular remodeling and function among college football players. Am J Cardiol 2013;112:128-34.

27. Kim JH, Baggish AL. Differentiating exercise-induced cardiac adaptations from cardiac pathology: the "grey zone" of clinical uncertainty. Can J Cardiol 2016;32:429-37.

28. Pelliccia A, Maron BJ, Spataro A, et al. The upper limit of physiologic cardiac hypertrophy in highly trained elite athletes. $N$ Engl $J$ Med 1991;324:295-301.

29. Parato VM, Antoncecchi V, Sozzi F, et al. Echocardiographic diagnosis of the different phenotypes of hypertrophic cardiomyopathy. Cardiovasc Ultrasound 2015;14.

30. Wigle ED, Sasson Z, Henderson MA, et al. Hypertrophic cardiomyopathy. The importance of the site and the extent of hypertrophy. A review. Prog Cardiovasc Dis 1985;28:1-83.

31. Basavarajaiah S, Boraita A, Whyte G, et al. Ethnic differences in left ventricular remodeling in highly-trained athletes relevance to differentiating physiologic left ventricular hypertrophy from hypertrophic cardiomyopathy. J Am Coll Cardiol 2008;51:2256-62.

32. D'Silva A, Sharma S. Exercise-induced cardiac remodeling: not a case of one size fits all. Circ Cardiovasc Imaging 2015;8. 